\title{
Representaciones de un mundo complejo: No tinc paraules de Arnal Ballester
}

\section{Estrella Sánchez Marcos}

\section{“Para Teresa Duran”}

La literatura infantil presupone un lector implícito al que las obras llegan a través de un intermediario. Hablamos así de un doble destinatario: niño y adulto. Ante este supuesto cabe pensar cómo es la relación del niño con el libro, si es libre o está socialmente planificada y protegida y cómo son los libros que esa estructura produce.

Los libros para niños son aquellos que escriben personas mayores, seleccionan personas mayores y compran personas mayores pensando en el disfrute de los niños. La mayoría de estos libros poseen imágenes que, cuando están trabajadas con rigor por un artista talentoso, son mucho más que una mera decoración o reclamo publicitario: se nos aparecen entonces como un verdadero lenguaje capaz de transmitir sustanciosas raciones de humor y de misterio a través de múltiples canales secretos (Ferrer 2005: 1).

Cada niño tiene sus propios mecanismos lingüísticos, afectivos y cognitivos para construir significado mediante el juego y el lenguaje, Vigotski (2003) señala cómo desde el principio de su vida, un niño enlaza emocionalmente su cuerpo con sus pensamientos e imágenes del mundo. Esa aprehensión simbólica le ayudará a ser parte de su cultura y a comprender "lo otro" como fundamento de lo colectivo y social, pero también de la representación, de la creación, de la metáfora.

Algunos autores, ilustradores y editores de libros infantiles defienden para su trabajo cierta complejidad en los contenidos y en la forma de mostrarlos. Su punto de partida es la consideración de que el niño es un ser inteligente, sensible, autónomo y un experto interpretador de códigos visuales y gráficos.

\section{Representaciones no visibles}

El contexto social y de mercado de la producción de libros infantiles actuales, dificulta la presencia de ciertos temas o motivos: la sensualidad, la muerte, el amor, el erotismo. Podríamos decir que son representaciones no visibles, que se corresponden a un momento de aligeración crítica e ideológica (Berger 2000). En las sociedades modernas del bienestar queda velado todo lo que pudiera ser inquietante, la reflexión sobre la identidad del ser humano y su forma de estar en el mundo es elusiva. ¿Existe entonces 
algún espacio en el que los niños puedan sustituir la realidad? ¿Podría ser el álbum ilustrado ese lugar?

\section{El libro álbum como medio}

Al delimitar un corpus en el que observar cómo esas representaciones se omiten o muestran, encontramos que el álbum ilustrado, con sus dos lenguajes narrativos, como artefacto abierto a los cambios, a la experimentación ${ }^{1}$, permite ponerlas en juego. Además, el álbum concebido como "forma de expresión específica” (Van der Linden 2007: 29) o como lenguaje hecho de imagen y texto, es idóneo para leer con niños muy pequeños:

Puesto que los álbumes pueden complicar las cosas, [...] la ilustración tiene un papel clave de mediación en el camino del lector incipiente hacia significados complejos, tanto si puede apreciarlos conscientemente, como si su efecto se mantiene implícito (Colomer 2002:8).

En el proceso de modernización de los libros infantiles es importante no perder de vista la renovación de formas promovida por los artistas de las vanguardias del período de entreguerras del siglo XX.

El inicio de toda esta utopía, destrozada con el inicio de la Segunda Guerra Mundial, se ha fijado en la exposición organizada por Blaise Cendrars en 1920, en la librería Bonaparte de París, sobre libros para niños realizados por artistas y escritores rusos tras la revolución soviética. Aquellas obras, como el arte que se producía en Rusia en esos años, estaba muy relacionado con las corrientes de vanguardia, en especial con el constructivismo, y reflejaba el interés de los artistas en lograr un lenguaje gráfico no minoritario que, conjugando tradición y modernidad, posibilitara un mejor acercamiento del arte moderno al universo infantil (Levéque y Pérez 2005:1).

Aunque el mundo de la literatura para niños fuera de la Unión Soviética no respondió de manera uniforme con una aceptación inmediata de formatos, conceptos de presentación u otras innovaciones observadas en el experimento soviético, sí se realizaron exposiciones de estos extraordinarios libros en Dinamarca y en ciudades como Ámsterdam a principios de los años treinta (Fraser 2005:39).

\section{Ideas en la gráfica}

Cuando un autor-ilustrador de literatura infantil actual decide mostrar en su trabajo motivos como la sensualidad, el erotismo, las relaciones de poder, la muerte, además de posicionarse en los márgenes, ¿qué ideas y representaciones maneja?, ¿cómo les da forma gráfica o textual?, ¿a qué modelos anteriores acude? 
En poco más de quince años han visto la luz en nuestro país trabajos renovadores tanto por su concepción formal como por las ideas movilizadas, son libros como Una casa para el abuelo y El libro de las preguntas de Isidro Ferrer; No tinc paraules o Bestiarara de Arnal Ballester, El monstruo de la lluvia de Pablo Amargo; el relevo de lo inquietante en Carmen Segovia o en los cuentos ilustrados por Ana Juan; mundos muy personales como el de Francis Meléndez, Alfonso Ruano, Pep Montserrat, Javier Sáez Castán, Elisa Arguilé, Miguel Gallardo, Luci Gutiérrez, Riki Blanco, Pere Ginard, etc. Entre ellos, el ilustrador Arnal Ballester aúna la experimentación gráfica y la presencia de ideas no siempre cómodas en sus libros dirigidos a los niños:

Intento que en mi trabajo se filtre libremente también lo inconveniente, lo escatológico, lo desagradable. ¿Podría ser de otro modo? Las imágenes de los libros como los juegos son ese espacio en el que podemos enfrentarnos a todo y aprenderlo todo sin pagar las consecuencias. Sin eso, ni los juegos, ni los libros, ni por supuesto sus ilustraciones, tienen ningún sentido (Ballester 2006: para 19).

Dedicaremos las próximas páginas a tratar de ver cómo se potencian esas líneas de fuerza en su libro No tinc paraules, trabajo que marca un cambio funcional en lo que tiene de explotación máxima de la gráfica al servicio del sentido creado por el lector, sea éste el niño o el adulto que está con él mientras lee.

\section{No tinc paraules en el contexto de la obra de su autor}

Arnal Ballester comienza a ilustrar libros destinados a niños a mediados de los 80. Su trabajo es deudor de los ilustradores y humoristas gráficos de los años 20 y 30: Opisso, Junceda, Nogués, Coll, así como de distintas tendencias artísticas procedentes de las vanguardias históricas. Ásun Balzola lo reconoce como renovador de modelos:

[...] y es que ahora hay sitio para todas las tendencias: [...] hay sitio para Arnal Ballester, que sí renueva a los maestros de la pre-guerra; hay sitio para Francisco Meléndez, que se pasea por el gótico o por la iconografía precolombina o por lo que le da la gana, etcétera (1992: 8-15).

Unos años después Joma (2000) en una entrevista breve y excelente, señala dos posibles líneas en su trabajo: una primera marcada por Hergé y los ilustradores españoles de la pre-guerra y una segunda de “orientación hacia el grafismo”:

\section{$1^{a}$. La línea y el color}

Tintín es el trasfondo de “Los artísticos casos de Fricandó”, una serie de cuatro libros escritos por Montse Ginesta que proponen el descubrimiento de un estilo artístico en 
cada uno (el Surrealismo, el Cubismo, el Pop-Art y el Arte Abstracto): La boca risueña (1992), Una dulce mirada (1992), Las dos manchas (1993) y La sombra negra (1994).

De Hergé vemos en ellos el humor como elección comunicativa, la composición, el uso de la línea y el color, la minuciosa descripción de personajes, objetos, localizaciones. También el dinamismo, las tramas, la tensión de lo inquietante y los elementos de intriga. Algunas de estas características se sumarán a otras comunes en la forma de trabajar de Ballester: la saturación de personajes y objetos en la página, el uso del fuera de campo, las referencias a la publicidad, las paradojas visuales al invertir convenciones de representación. Son interesantes estos libros porque el uso de los estilos artísticos en sus ilustraciones será explícito, hiperbólico. Están construidos de forma que “recuerden a”...Miró, Picasso, Magritte, Warhol, Lichtenstein, etc., y sin embargo la gráfica base es la de Hergé. Ana está furiosa, Simón el dragón o los cuentos ilustrados para La Galera estarían dentro de esta línea.

\section{$2^{a}$. La orientación hacia el grafismo}

Humor y grafismo serán una constante en el trabajo de este ilustrador. En la segunda línea confluyen además de los ilustradores españoles mencionados, Tono y K-Hito; los humoristas gráficos: Mandrika, Topor, André François, Edward Lear, Grandville; los pintores y dibujantes de entreguerras: Saúl Steinberg, Grosz, Frans Masereel, Ben Shan; los ilustradores o artistas europeos vinculados a las vanguardias: Franciszka Themerson; Miroslav Sásek; en España el juego formal de Joan Brossa, Daniel Gil, Manolo Prieto. Están los constructores de objetos, artefactos y juguetes: Calder, Torres García, Duchamp.

Apuntaba Ásun Balzola (1992) tres características importantes de lo que empezaba a ser la ilustración española en aquel momento: ruptura, reconquista del humor y recuperación de modelos de ilustradores de pre-guerra e internacionales. En ese marco multi-referencial Arnal Ballester sintetiza un estilo propio, el “constructivismo racionalista” (Iranzo 2006) que se apoya en el Surrealismo y el Constructivismo ruso. Este último quizás fue el movimiento artístico de vanguardia con el fundamento teórico, plástico e ideológico más liberal. Era la experiencia de lo pictórico sobre los temas, el arte sin objetos. Arte aplicado a la idea de construcción de un hombre nuevo en el proyecto revolucionario y su posterior trasplante a los modelos funcionalistas de la Bauhaus de Walter Gropius. 
Ahora el trabajo gráfico es más denso, están la ruptura de las vanguardias, la metaficción, la red de relaciones y citas intertextuales, pero en esa puesta en evidencia de mecanismos de construcción, en la experimentación y búsqueda de lenguajes visuales y narrativos, hay una preocupación por el sentido, por las ideas a comunicar al lector: "Hi havia una necessitat de dignificació gràfica. De trencar el clixé del nen minusvàlid mentalment. Darrere l'atenció a la qüestió gràfica hi ha idees. L’oposició grafisme versus informació és falsa” (Joma 2000: 15)².

La leyenda de Guillermo Tell, No tinc paraules, Un cocodrilo bajo la cama, Bestiarara, Base y el generador misterioso, Chamario, así como los trabajos de animación actuales, formarían parte de esta segunda línea. Entran así en sus libros temas universales y complejos: la reflexión sobre la identidad y el erotismo en No tinc...; la segregación y la xenofobia en Bestiarara por ejemplo. El discurso es directo y claro, busca cierta complicidad con el lector a través del desafío, del reto y del juego. Elementos y temas constantes en este autor que responden a una forma marginal o “desmarcada” de tomar posición frente a los discursos culturales canónicos.

\section{Los libros sin palabras}

Los libros sin palabras realizados con grabado sobre madera tuvieron un desarrollo central en la Europa de entreguerras del siglo veinte. En 1918 aparecen los primeros libros de xilografías de Frans Masereel, un historietista, pintor y grabador belga. En Wordless books, David A. Beronä (2008: 11-12) explica cómo en el momento en que Masereel creó sus libros sin palabras había tres medios paralelos que permitieron su desarrollo y enorme aceptación:

1. Esta técnica es utilizada entre 1907 y 1927 por los pintores expresionistas alemanes para crear libros ilustrados: Kokoschka, Kirchner, Heckel. Masereel estará cercano a ellos por las bases ideológicas del uso del grabado: la visión crítica de la ciudad, la guerra, etc.

2. En segundo lugar, el creciente interés del público del momento por el cine mudo, El Gabinete de Dr. Caligari de Wiene es de 1920. Su gran aceptación como forma de entretenimiento e información favorece que estos libros sean relacionados con la imagen en blanco y negro, muda y en movimiento, y que compartan lenguajes narrativos. 
3. La aparición de historietas o tiras cómicas en los periódicos de la época, como las de Töpffer o The Yellow Kid de Outcault (1895), acentúan la eficacia crítica de la unión de humor y sátira.

Denunciaba en sus imágenes secuenciadas, provocativas e irreverentes, la paradójica relación del hombre con las nuevas sociedades industriales, el desarraigo y la desmesura en el lujo, la miseria y la enorme violencia vivida por los europeos durante la I Guerra Mundial:

Ahí estaba Frans Masereel, quien con sus grabados en boj contra la abominación de la guerra, dibujaba ante nuestros ojos su eterno monumento gráfico, esas inolvidables láminas en blanco negro que, por su fuerza y furia, no se quedaban a la zaga de, por ejemplo, Los desastres de la guerra de Goya. [...] cada mañana La Feuille publicaba una de sus acusaciones gráficas, que no acusaban a ninguna nación en concreto, sino siempre a nuestro común enemigo: la guerra (Zweig 2008: 340-342).

Será en estos libros sin palabras en los que Arnal Ballester encuentre un modelo cinematográfico primitivo en el que sustentar su No tinc paraules, a dos tintas, en movimiento constante:

In Arnal Ballester's No tinc paraules (pictured) monsters are created by projecting the silhouette of a hand into a room. [...] It provides a perfect vehicle for the illustrator to examine his/her art, because there is nothing to fall back on except technique and visual ingenuity. If nothing else, the wordless narrative provides a discipline and a challenge (Richards 2003: 26-29) ${ }^{3}$.

Si bien es cierto que es una obra donde el placer de los significantes está en primer plano y es inmenso, va más allá de ser un mero experimento gráfico, porque contiene ideas fundamentales sobre la identidad, la amistad, la solidaridad, la exclusión o las relaciones personales y de poder.

\section{Avanzando dentro del libro: una historia animada}

Paratextos: el libro como un todo para producir sentido

Los paratextos son muy significativos en los libros de Arnal Ballester, contribuyen a que el libro esté cuidado, aportan claves de lectura y estilo. Son, a veces, juegos metaficcionales, de simetría, paradojas visuales: 


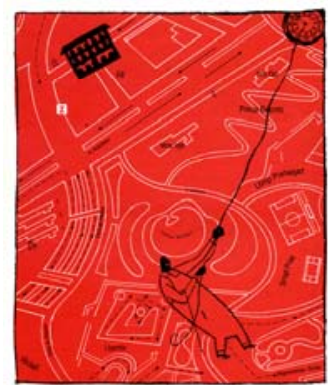

Ilustración 1:

(c) Arnal Ballester. Del libro No tinc paraules,

Valencia: Media Vaca, 1998. (Portada)
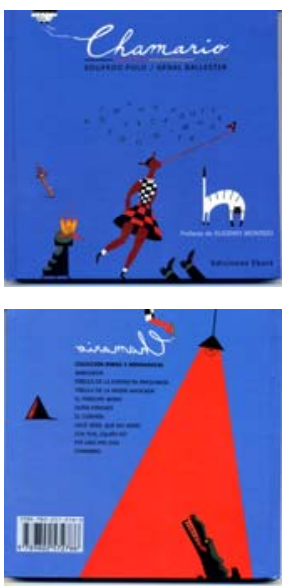

Ilustración 2:

(C)Arnal Ballester. Del libro Chamario, de Eugenio Montejo (textos) y Arnal Ballester (ilustraciones), Caracas: Ekaré, 2005

(Portada y contraportada)
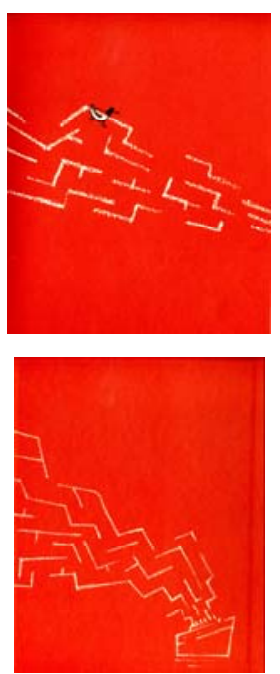

Ilustración 3:

(c) Arnal Ballester. Del libro No tinc paraules, Valencia: Media Vaca, 1998 (Guardas)

En la portada y las guardas de No tinc paraules un hombre negro en un muelle sujeta un reloj-globo mientras saluda sonriente a un barco que se acerca al anochecer. La oscuridad es de color rojo. Aquí ya están descritos y condensados la mayoría de los elementos de la narración, así como una serie de elecciones del ilustrador: bi-tono cromático, presentación del personaje, una inhabitual forma de relacionarse con los objetos, una ilustración hecha mediante figuras lineales, la muestra explícita de la convención gráfica en el humo del barco y los patos. No tinc paraules es un libro de pistas, de viaje nocturno. Pronto nos hacemos a la idea de que hay que encontrar algo y retener lo que vamos viendo. El lector no sólo tiene que jugar sino reconstruir o “montar” esas imágenes sucesivas y abiertas.

\section{Un aire de reto: representación e ilustración}

Representar significa estar en lugar de, sustituir, hacer presente algo que está ausente (Gombrich 2002: 1-29). El análisis de la representación nos permitirá conocer la relación entre el mundo real y el mundo recreado.

Si la representación es natural, el referente y su imagen tienen una relación analógica; ahora bien, si la representación se aleja de su referente, lo rompe y mira por dentro, produce varios efectos en el lector: sorpresa, extrañeza, diversión, convivencia con el absurdo, desplazamiento de expectativas. 
En No tinc paraules, su autor quiere poner distancia entre la imagen y su referente, entre las asociaciones de nuestra memoria y las convenciones en la representación de algunos personajes, lugares o acciones. Para anticipar lo que vendrá, será necesario volver atrás y reelaborar aquello que hemos visto. Tendremos que renunciar a la comodidad de sentirnos seguros en lo que estamos leyendo porque nuestra experiencia tropieza con trampas e inusitadas formas de ver el mundo. De esta manera todo tendrá un aire de reto. La forma de avanzar en la historia requerirá una importante creación de sentido por parte del lector, que es invitado a participar en un juego lleno de pistas.

\section{Los tres niveles de la representación}

La composición de este libro mediante imágenes secuenciadas, nos hace pensar en su carácter cinematográfico. Por este motivo nos será útil el método de análisis fílmico de Casetti y Di Chio (1991). Estos autores establecen tres niveles básicos de la representación:

$1^{\circ}$ Cuando miramos un álbum, vemos algo o a alguien que aparece ante nuestros ojos: es el nivel de los contenidos o de la puesta en escena.

$2^{\circ}$ Lo que vemos se nos muestra de una forma peculiar, el escenario está captado en plano general o en detalle, se sigue a los personajes o se los abandona por un rato, es el nivel de la modalidad de la representación o puesta en cuadro: así comienza nuestra historia, en un marco pequeño vemos el mapa de una ciudad, en detalle está el icono de una construcción, ¿con luz? La representación comienza siendo icónica.

$3^{\circ}$ Por último, lo que vemos sigue a lo que hemos visto antes y a la vez prepara lo que vendrá. El escenario y la acción pueden cambiar, los personajes siguen con la misma actitud o la corrigen, estamos en el nivel de los nexos, de la relación temporal y espacial de unas imágenes con las otras, llamado también montaje. En No tinc paraules sólo están ilustradas las páginas de la derecha; las de la izquierda están en blanco. Para avanzar en la historia, tendremos que pasar página como si se tratase de fotogramas de un film. Pero habrá una diferencia importante del álbum con respecto al cine, el ritmo de la mirada del lector lo decidirá sólo él, podrá ir atrás y adelante en las páginas, ventaja fundamental para descubrir las pistas. 


\section{Estructura narrativa}

La estructura viene definida por transformaciones narrativas indicadas por marcas formales (tamaño de marcos, etc.). El esquema podría ser así:

1. Historia marco: en un anochecer vemos una construcción en el mapa de una ciudad. Un hombre negro coge por un cordel un reloj suspendido en el aire y camina por el mapa. Se aproxima al puerto. Saluda a un barco que llega. Salen a recibirle dos personajes que dan muestras de nerviosismo: una chica-Bunnie, como sacada de un espectáculo de varietés, y una jirafa.

2. En el barco-circo: la cabeza del mago ha desaparecido.

2.1. Primera voz que cuenta lo sucedido: una vez dentro del barco un reportero años 30 cuenta cómo el cuerpo del mago ha desaparecido. El principal sospechoso parece ser un tigre. El hombre-detective comienza un recorrido por el barco en el que observa a los distintos artistas de un circo mientras ensayan. Hay animales exóticos, objetos extraños...

2.2. Segunda voz que cuenta lo sucedido: el detective escucha la versión del tigre. Éste explica su amistad con el mago y cómo un gran tigre les amenazó en otra ocasión.
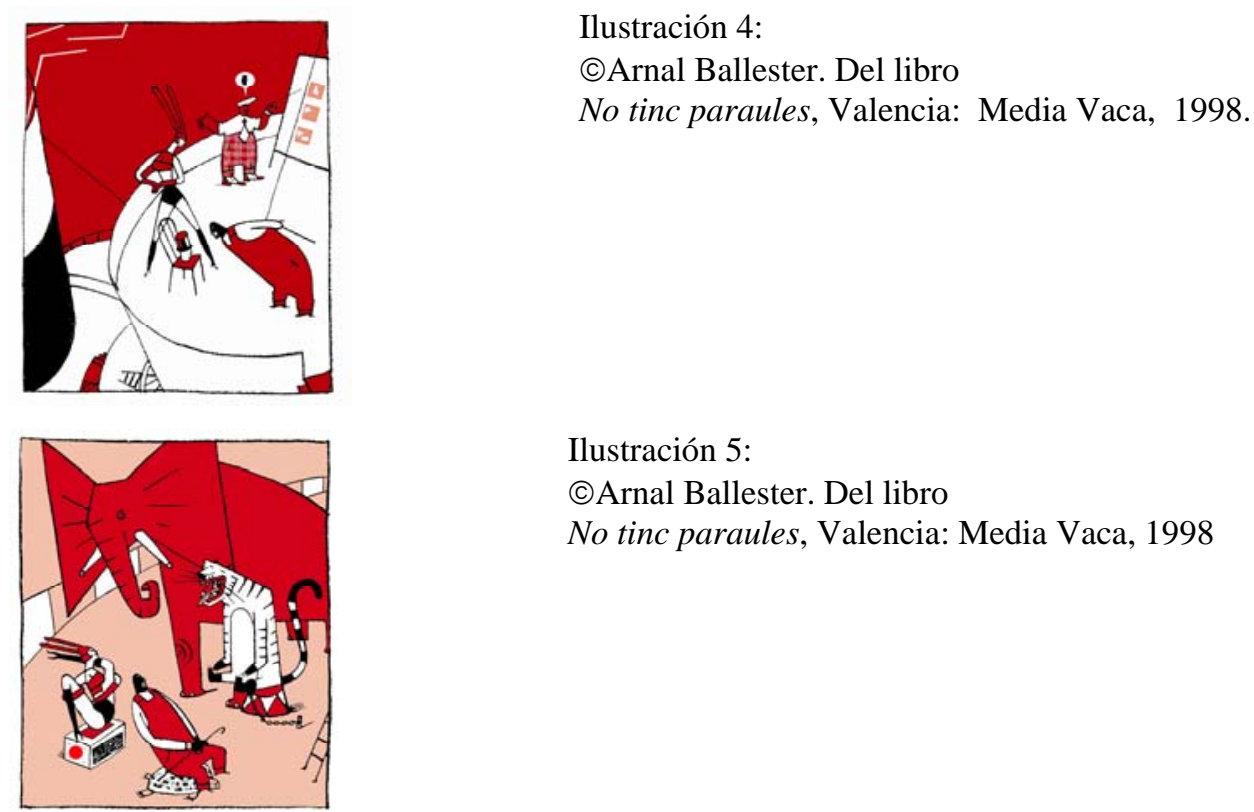

Ilustración 5:

(C) Arnal Ballester. Del libro

No tinc paraules, Valencia: Media Vaca, 1998

2.3. Clímax: comienza con una escena en la que muchos personajes del circo contemplan el número de los payasos, pero lloran, están tensos ¿por qué?, ¿qué ha cambiado? A partir de ahora el antagonista empieza a mostrarse, a lanzar amenazas visuales mediante sus sombras. En esta parte se produce un giro con respecto a los mecanismos de distanciamiento: la implicación de los artistas del circo en los sucesos 
hace que el lector se sienta involucrado en la historia y empujado a tomar partido. De hecho, en ese momento seguramente el lector es el único que ya ha podido averiguar quién es el impostor, porque las pistas dejadas son visibles sólo para él; ni el detective ni los artistas parecen saberlo aún. El autor le ha convertido en su cómplice.

Ha llegado la hora de tratar de recopilar todos los datos y pistas. Mientras tanto el tiempo corre en el reloj. El detective descubre la clave, sólo un personaje puede crear un doble del tigre. Comienza el desenmascaramiento del impostor, la persecución, la recuperación del cuerpo del mago, la expulsión del traidor del circo, alegría general y celebración.

3. Historia marco, cierre: el detective, en el regazo de la trapecista, mira el reloj y emprende su camino de vuelta, se despide, deja el barco, regresa al anochecer, desde el puerto, caminando por el plano de la ciudad hacia la casa de la que salió, su tiempo parece limitado y, a su espalda, todo se vuelve línea, irrealidad. No obstante, quedan olvidados fragmentos de un mundo en el otro, como el corazón, mariposa que va y viene.

Los espacios de la representación: el fuera-de-campo como recurso central en Arnal Ballester

Casetti y Di Chio (1991) se refieren al espacio que está dentro del marco como campo $\mathrm{y}$, al que no lo está, como fuera-de-campo. El juego dentro/fuera es fundamental para entender esta historia, muchas pistas estarán más allá de los bordes del marco, pero también los mensajes estarán fuera, serán extranjeros en una ideología dominante. Aquello que queda fuera-de-campo es significativo porque se organiza en ese eje central/marginal.

El fuera-de campo (o espacio Off) puede darse de dos formas:

por colocación: a los lados de la imagen, arriba, abajo, al fondo (delante de la cámara) y detrás de la cámara. En No tinc... los personajes entran y salen por todos los lugares posibles de la página, caminan en todas las direcciones, “atraviesan” la virtualidad del formato físico para bajar o subir dentro del libro. Encontramos una translocación del punto de vista, parece que el lector ve lo mismo que el detective, desde la misma situación y sin embargo no es así. Este mecanismo producirá relaciones de empatía, como si no se abandonase al lector en su lectura.

por determinabilidad: ese espacio que no vemos puede ser:

-espacio no evocado (el que no está definido), 
-espacio imaginable (el que se supone aunque no se muestre, como el mar por el que navega el barco),

-espacio definido (el que ya se ha visto antes o se va a ver después, como puede ser el plano de la ciudad).

Los dos últimos son importantes para la gestación del argumento y personajes de No tinc paraules. Es espacio imaginable aquél en el que está el ilusionista cuando sólo vemos las sombras que sus manos fabrican. Al espacio definido pertenecen fragmentos de la carpa del circo, de objetos o personajes: las piernas, una pata, medio cuerpo, un trazo de línea de compás. Primero aparece un trozo de algo no muy reconocible, el lector aprende pronto a retener cada pequeño detalle, esperar hasta encontrarlo contextualizado y adivinar qué es.

Esos juegos de ruptura o continuidad de la percepción visual, de falsos raccords, de montaje y construcción a través de los nexos o elipsis entre las imágenes, provocan sorpresa e insisten en una forma de leer en el relato muchas historias posibles.

\section{Voces que cuentan: marcos y nexos}

Hemos visto cómo los marcos definen tanto las relaciones compositivas en el interior de las imágenes como las asociaciones entre unas y otras.

En No tinc paraules los marcos cambian de tamaño en dos momentos relevantes:

En el primer momento los tamaños de marco sirven para señalizar la historiamarco: la salida del vigilante por el mapa, el marco se irá agrandando en un zoom hacia atrás, y el regreso del vigilante, el marco va empequeñeciendo en un zoom hacia delante. El reflejo y el juego con la simetría es un recurso utilizado con frecuencia por este ilustrador como forma de pensar en la identidad, de producir paradojas visuales, ópticas, a ambos lados de un eje horizontal o vertical. La imagen reflejada de un ser de ficción en un espejo dibujado es como poner en abismo una idea.

El segundo momento en que los marcos cambian corresponde a las dos versiones que reportero y tigre dan sobre los hechos. Es un modo de introducir varias voces mediante un recurso gráfico muy interesante, más en un libro sin palabras en el que resolver este problema presenta cierta complejidad. En un marco superior aparece lo narrado y en uno pequeño inferior, el narrador. Las tintas empleadas y la trama también son diferentes.

Primera versión sobre la desaparición del cuerpo del mago: aparecen por primera vez, “en ausencia” los protagonistas del suceso: el mago y el tigre. 


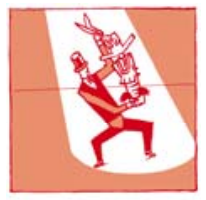

Ilustración 6:

(C)Arnal Ballester. Del libro

No tinc paraules, Valencia: Media Vaca, 1998

Segunda versión: es narrada por el tigre de forma oral a la Bunnie, al detective y a un elefante que parece ser su defensor. Este momento es crucial para el lector, porque mientras los personajes escuchan al tigre, el lector ve las imágenes y, como en ellas está la clave de lo ocurrido, identificará antes que nadie al culpable. El tigre ofrece una versión subjetiva de lo sucedido. A partir de aquí el detective continúa solo la búsqueda, sacando sus propias conclusiones de lo que ve. De igual modo, el lector tiene que analizar, no creer todo aquello que se le cuenta y construir su propia historia.

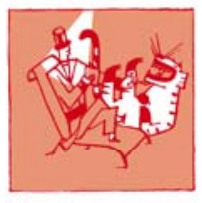

Ilustración 7:

(c) Arnal Ballester. Del libro

No tinc paraules, Valencia: Media Vaca, 1998

Bajtin (1974; 1989) analiza el diálogo en la novela como una construcción participativa en la que cabe lo diverso, la “polifonía de voces” frente al carácter discursivo dominador de la retórica clásica. La obra de Arnal Ballester está en los márgenes, busca las posibilidades formales y de significado del exilio, de lo fronterizo. Los personajes de No tinc paraules son de distintas razas, países, son hombres, mujeres y animales, algunos incluso son iconos, señales o símbolos.

Una pipa, un huevo y la acacia: metaficción en álbum infantil

Cuando vemos una pipa dibujada bajo la que pone “esto no es una pipa” la paradoja denuncia su "ser fabricado". Si vemos un huevo dibujado bajo el que leemos "la acacia”, lo que tenemos es una metáfora vanguardista, en la cual la asociación entre los términos es libre y poco convencional. Es una metáfora disímil, dispar, que relaciona significantes nunca antes puestos en contacto. Es la metáfora propia del montaje, del collage, del fondo onírico del Surrealismo. 
En nuestra historia, los significados iniciales están desplazados hacia otros metafóricos: un reloj que vuela puede ser globo; un mapa es una ciudad; un corazón, una mariposa y una bombilla eléctrica, el sol. Serán representados en un espacio negado, no analógico, del que nunca vamos a ver el todo, característico del lenguaje de las vanguardias (Casetti y Di Chio 1991).

Cecilia Silva-Díaz (2005) ha definido los mecanismos de metaficción en los álbumes infantiles actuales: el cambio en la perspectiva de quien cuenta la historia, la alteración de la jerarquía de las diferentes historias, la transgresión de la frontera entre lo que está dentro y fuera (soporte, libro, papel), la recontextualización de las formas del pasado, etc. También señala varios principios-efecto que pueden aparecer en las narraciones metaficcionales como la indeterminación, la intertextualidad, el cortocircuito y la consideración del lector como un jugador.

La metaficción se conjuga muy bien con dos verbos: 'vulnerar’ y 'descubrir'. En la literatura infantil la metaficción vulnera o descubre las convenciones de una literatura que, debido a su lector implícito, tiende a presentar una visión del mundo sin contradicciones, a desarrollar un solo hilo argumental, a los finales cerrados, en vez de los abiertos, a estar focalizada en un personaje, a no presentar variaciones estilísticas, etc.

No tinc paraules: algo extraño pasa dentro del libro

¿Por qué el personaje no camina por una ciudad real? ¿Por qué no lleva su reloj en el bolsillo? ¿Por qué hay un marco que limita la imagen si hay mucha imagen que queda fuera de él?

En No tinc paraules encontramos diferentes recursos metaficcionales que causan en el lector un efecto doble de distancia-cercanía. La diferencia entre que un personaje camine por una ciudad llena de gente a que lo haga por un mapa de ciudad, lleno de convenciones gráficas, de signos, tiene una base de trabajo semiótica, pero su impacto en el lector es sobre todo de índole afectiva. En estas imágenes vemos la diferente forma que el autor tiene para comunicarse con su lector al crear el personaje de Fricandó o el detective que nos ocupa: 


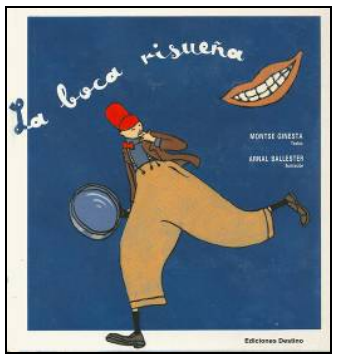

Ilustración 8:

(C)Arnal Ballester. Del libro La boca risueña de Montserrat Ginestra (textos) y Arnal Ballester (ilustraciones).

Barcelona: Destino, 1992

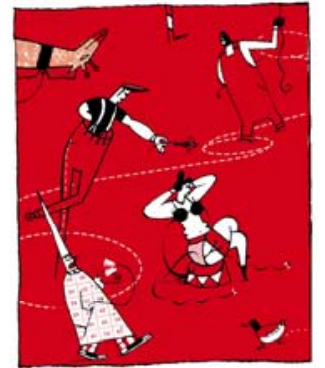

Ilustración 9:

(c)Arnal Ballester. Del libro No tinc paraules, Valencia: Media Vaca, 1998.

En No tinc paraules, representación y referente guardarán una distancia que hará muy difícil la identificación de y con el protagonista: sus gestos, indumentaria o edad se vuelven ambiguos.

Son varios los mecanismos de lejanía que Arnal Ballester utiliza y que, sin embargo, se transformarán en un discurso más afectivo para el lector:

- La historia-marco de un vigilante de una ciudad, que vive y camina por un mapa, evidencia lo ilusorio, la irrealidad de lo narrado.

- Cuando el vigilante entra en el barco-circo no se sorprende de lo que allí encuentra, no hay demasiado énfasis emocional por la decapitación del mago.

- La composición de la imagen dentro de un marco negro, rodeado por el borde blanco de la página, parece indicar que todo sucederá dentro de campo. No obstante, esos límites están ahí para ser traspasados continuamente y para jugar a hacer relaciones dentro/fuera y adelante/atrás, desplazando los raccords de mirada y movimiento, los códigos sintácticos, las elipsis temporales. Este recurso del marco en ilustración de álbum es una decisión del ilustrador, no lo da el medio como pasa en el cine. Si el autor lo elige es porque quiere distanciar al lector de lo representado. Aquí, con una página ilustrada y una página blanca tras otra, y con el marco aislando el campo, la ruptura de la ilusión es constante. Ahora bien, si el lector se implica, si mueve las páginas hacia adelante y atrás, se detiene, busca, está provocando una sensación de movimiento similar a la que realizan el ojo y la mente al ver un film (Arnheim 1991).

- $\quad$ El tiempo es circular, la situación de partida y la de llegada son casi simétricas. La medida del tiempo, aunque parece clara y marcada por el reloj, es también una ilusión: ¿cuántos días han pasado? Éstas son pistas que semejan repetición, circularidad en los hábitos del vigilante, negación del viaje insólito del que regresa. 
- $\quad$ Los personajes son muchos, la saturación y movimiento constante en la página: unos son parte de la historia (tigre, vigilante) y otros del relato: los gatos erizados señalan el peligro; los patos revelan un espacio ficticio.

- También se ve alterada la convención visual narrativa de movimiento y posición, los personajes caminan de derecha a izquierda o al contrario, aparecen por arriba, por abajo, vienen del fondo y salen por el frente, descienden por el suelo. Su posición puede ser denotativa (patos, gatos) o connotativa: el detective muchas veces observa, como el lector, desde posiciones marginales. Las indicaciones espaciales son confusas. La falta de profundidad de campo o la falsa continuidad espacial dan sensación de desubicación, de ir por un laberinto.

- La luz y la sombra serán muy inusuales. En el exterior del barco hay oscuridad, en el interior una luz que apenas produce sombra. El único que maneja luz directa y sombra es el antagonista. El detective, para vencerle, le ataca con la luz de su linterna. La falta de sombra muestra a los personajes y objetos como irreales, aunque en esta ocasión habla de un mundo aún más virtual, el de las sombras hechas con las manos.

- $\quad$ En el uso de elementos publicitarios como la hojilla La Palmera, los niños perciben el efecto cómico que provoca su uso hiperbólico o anacrónico, aunque puedan estar alejados de su experiencia. Detrás está el Pop-Art.

- Existen citas intertextuales de obras y artistas del s.XX: la cebra en cierto momento nos recuerda a El Guernica de Picasso, también la bombilla-sol; aparecen los puntos bendéi de Lichtenstein; en los escenarios del circo podríamos ver los decorados teatrales de Popova, etc. Pero éstas no son referencias explícitas o literales siempre, si no que se producen en niveles profundos de composición y estilo. Las citas igualmente son de autores y textos literarios, la naturalidad del absurdo de ciertas situaciones y personajes recuerdan a Gogol, a Bulgakov.

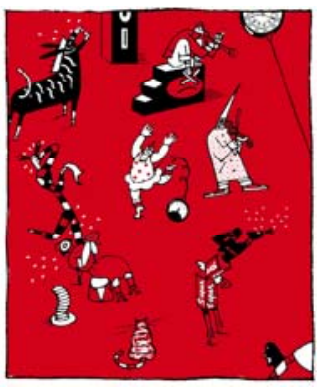

Ilustración 10:

(C) Arnal Ballester. Del libro

No tinc paraules, Valencia: Media Vaca, 1998 
El cuerpo en el espacio: levedad

Los personajes de los libros de Arnal Ballester están constantemente suspendidos entre el espacio y el tiempo. Hay un momento en que Ásun Balzola relaciona este estilo de ilustración con la idea de “Levedad” de Italo Calvino (1990): la levedad en contraste con el peso, pero a su vez como precisión y percepción de lo infinitamente minúsculo, móvil, donde el vacío es tan concreto como los cuerpos sólidos.
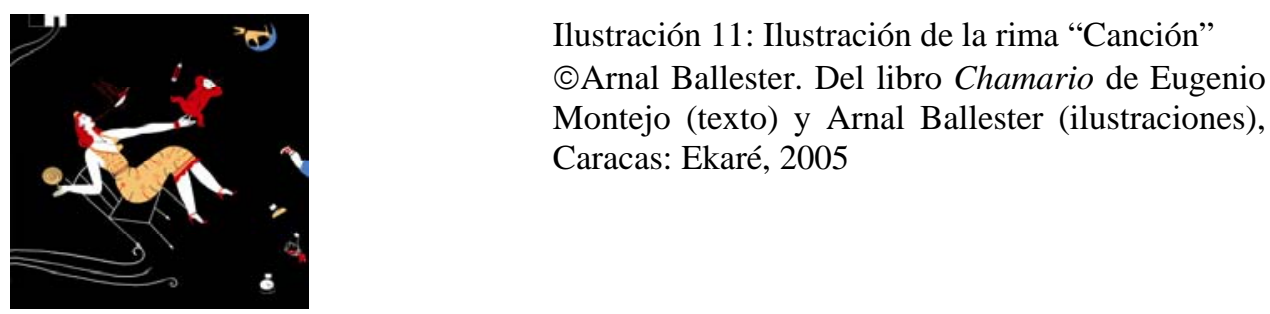
(C)Arnal Ballester. Del libro Chamario de Eugenio Montejo (texto) y Arnal Ballester (ilustraciones), Caracas: Ekaré, 2005

La presencia de los cuerpos es electrizante, sensual y táctil en todo su trabajo. Son caminos posibles y elecciones entre formas de ser, de mostrar el cuerpo, entre distintos momentos culturales e históricos. La recuperación de las representaciones del cuerpo está cambiando en una sociedad en la que las formas de tratarlo han sido cuestionadas ${ }^{4}$. Pero siguen existiendo espacios inmensos ocupados por la cultura del cuerpo negado y sus no-representaciones.

En No tinc paraules el autor, al desvelar el engranaje, se queda de alguna forma dentro y no abandona al lector. El posible puente, que permite al niño cruzar y adentrarse en ese mundo insólito, está tendido entre la compañía y el humor. La primera visibiliza la voz del adulto acompañante en la lectura como parte de ese doble destinatario. Y respecto al humor, ¿quién dijo que el humor no esté cargado de afecto? Un trabajo así en un mercado editorial como el nuestro habla de una generosidad inmensa por parte del ilustrador y del editor. Está concebido para hacer presente lo que no tenemos, creado no como arte, sino como un caballito de madera.

\section{Referencias Bibliográficas}

Arnheim, R. (1991) Arte y percepción visual. Madrid: Alianza.

Arizpe, E. y Styles, M. (2004) Lectura de imágenes. Los niños interpretan imágenes visuales. México: Fondo de Cultura Económica.

Bajtin, M. M. (1974) La cultura popular en la Edad Media y el Renacimiento. El contexto de François Rabelais. Barcelona: Barral.

Bajtin, M. M. (1989) Teoría y estética de la novela. Madrid: Taurus.

Ballester, A. (1998) No tinc paraules Valencia: Media Vaca.

Ballester, A. (2006) Ilustrando sin niños delante. Gretel-UAB. Máster en Libros y

Literatura para Niños y Jóvenes. Visto el 12/2/2009 en: 
http://www.pangea.org/greteluab/index.php?option=com_content\&task=view\&i $\mathrm{d}=107 \&$ Itemid $=119$

Balzola, Á. (1992) Escuela de ballenas. CLIJ. Cuadernos de literatura infantil y juvenil, 32, pp. 8-15.

Berger, J. (2000) Modos de ver. Barcelona: Gustavo Gili.

Beronä, D. A. (2008) Wordless Books: the original graphic novels. Nueva York: Abrams.

Calvino, I. (1990) Seis propuestas para el próximo milenio. Madrid: Siruela.

Casetti, F. y Di Chio, F. (1991) Cómo analizar un film. Barcelona: Paidós.

Colomer, T. (dir.)(2002) Siete llaves para valorar las historias infantiles. Madrid: Fundación Germán Sánchez Ruipérez.

Durán, T. (2001) Panorama actual de la ilustración española. Platero, 125, pp.11-13.

Durán, T. (2005) Ilustración, comunicación, aprendizaje. Revista de Educación, número extraordinario.

Durán, T. (2007) Àlbums i altres lectures. Anàlisi dels llibres per a infants. Barcelona: Rosa Sensat.

Durand, M. y Bertrand, G. (1975) L’image dans le livre pour enfants. París: L’École des Loisirs.

Escarpit, D; y Vagné Lebas, M. (1988) La littérature d'enfance et de jeunesse. Etat des lieux. París: Hachette.

Ferrer, V. (2005) El gabinete de un aficionado. Exposición 17 Libros para niños ilustrados, Valencia: MuVIM, 23 de junio-15 de septiembre.

Fraser, J. (2005) El libro para niños en la Unión Soviética de los años veinte. El libroálbum: invención y evolución de un género para niños. Caracas: Banco del Libro.

Ginesta, M. y Ballester, A. (il.) (1992) La boca risueña. Barcelona: Destino.

Gombrich, E. H (2002) Meditaciones sobre un caballo de juguete. Madrid: Debate.

Iranzo, C. (ed.) (2006) Entrevista a Arnal Ballester. En: 6 ilustradores opinan. Panorama de la ilustración de autor en España, pp. 15-39. Murcia: Ayuntamiento de Murcia.

Joma (2000) Arnal Ballester i la vivència d'ilustrar. Faristol, 36, pp.14-17.

Lapointe, C. (1995) Les chevaux et les sorciéres. Les différents styles graphiques transforment l'image et changent la perception des objects représentés. Barcelona: Ponències del Tercer Simposi International Catalònia d'Il.lustració. Generalitat de Catalunya. Departament de Cultura.

Levéque, F. y Pérez C. (2005) Libros infantiles 1920-1940. Exposición realizada en Valencia: MuVIM, junio-septiembre.

Montejo, E. y Ballester, A. (il.) (2005) Chamario. Caracas: Ekaré.

Richards, B. (2003) Shhhh! Frans Masereel and beyond, reflections on the wordless narrative. The Journal of the Association of Illustrators (AOI), pp. 26-29. Londres: agosto/septiembre.

Silva-Díaz, M. C. (2005) La metaficción como un juego de niños. Una introducción a los álbumes metaficcionales. Caracas: Banco del libro.

Van Der Linden, S. (2007) Lire l'album. París: L’Atelier du Poisson Soluble, Le Puyen-Velay.

Vigotski, L. S. (2003) La imaginación y el arte en la infancia. Barcelona: Akal.

Zweig, S. (2008) El mundo de ayer. Memorias de un europeo. Barcelona: Acantilado. 
Referencia de la autora:

Estrella Sánchez Marcos (Salamanca, España, 1967) es licenciada en Filología Hispánica por la Universidad de Salamanca (1991). Recibió el Premio Letras Jóvenes Junta de Castilla y León en 1995. Obtuvó el Máster en Libros y Literatura para niños y jóvenes de la Universitat Autònoma de Barcelona y el Banco del Libro de Venezuela-Fundación Germán Sánchez Ruiperez en 2005. Actualmente trabaja como bibliotecaria en la Sección Infantil y Juvenil de la Red de Bibliotecas Públicas Municipales de Salamanca (Spain).

Email: estrellasm@telefonica.net

\footnotetext{
${ }^{1}$ Para la concepción de la ilustración como lenguaje narrativo: Durand y Bertrand (1975), Escarpit y Vagné Lebas (1988), Lapointe (1995), Durán (2001, 2005, 2007), Colomer (2002), Arizpe y Styles (2004), Silva-Díaz (2005), Van der Linden (2007). Teresa Duran explora de forma clarificadora las vías de comunicación del ilustrador hacia el lector.

2 "Había una necesidad de dignificación gráfica. De romper el cliché del niño mentalmente minusválido. Detrás de la atención a la cuestión gráfica hay ideas. La oposición grafismo versus información es falsa”.

3 "En el ilustrado No tinc paraules de Arnal Ballester, los monstruos son creados al proyectar la silueta de la mano en un espacio [...]. Este recurso ofrece un vehículo perfecto al ilustrador para examinar su arte, porque no haya nada de lo que echar mano excepto de la técnica y la habilidad visual. Si no otra cosa, la narrativa sin palabras proporciona disciplina y reto".

${ }^{4}$ Berger evalúa la forma en que se muestra el cuerpo femenino en distintos medios comunicativos o artísticos como una relación de dominio constante (2000: 53-74).
} 